\title{
The various topics relating to education and information technologies
}

\author{
Arthur Tatnall
}

Published online: 12 April 2011

(C) Springer Science+Business Media, LLC 2011

This issue of the journal covers a broad range of topics, ranging from discussion of learning technologies themselves to student experience in virtual learning environments. These articles are: 'Students' communicative behaviour adaptability in CSCL environments', 'Medium for empowerment or a centre for everything: Students' experience of control in virtual learning environments within a university context', 'An architectural specification for a system to adapt to learning patterns', 'Physical education and sport science undergraduate students as multimedia and web developers: Moving from the user's to the creator's perspective', and 'E-books as support for emergent writing with and without adult assistance'.

Despite this diversity however, there are many areas relating to ICT and education that are not currently being covered by articles submitted to the journal. As I mentioned in an earlier editorial, this journal is the official research outlet for IFIP TC3. (The International Federation for Information Processing (IFIP) is the world peak body for Information and Communications Technologies (ICT) and its membership includes computing societies from many countries around the world.) This is a significant group and this journal should reflect this significance.

IFIP Technical Committee TC3 is the group concerned with matters relating to Computing and Education and has Working Groups and Special Interest Groups covering the following areas: Secondary Education, Higher Education, Research, Professional and Vocational Education, Primary Education, Distance Education, Educational Management, Lifelong Learning and Digital Literacy. We are still, however, not seeing articles covering all these areas. There have, for instance been few articles relating to educational management or to professional and vocational education. In the past there have been articles on national education policies and initiatives but we have not seen any such articles recently.

\footnotetext{
A. Tatnall $(\bowtie)$

Graduate School of Business, Victoria University, Melbourne, Australia

e-mail: Arthur.Tatnall@vu.edu.au
} 
I would like to see a greater range of articles submitted to the journal. Our area of interest is now quite mature, but still evolving in many directions. It would be good for the journal to reflect this evolution with some exploratory articles that questioned where we are going and why, and it would be especially good if each IFIP TC3 working group contributed regularly to the journal. 